\title{
Coronavírus bovino (BCoV) e sua analogia ao SARS-CoV-2 - Revisão de literatura
}

\author{
Bovine coronavirus $(\mathrm{BCoV})$ and its analogy to SARS-CoV-2 - Literature review \\ Coronavirus bovino (BCoV) y su analogía con el SARS-CoV-2 - Revisión de la literatura
}

Recebido: 15/11/2021 | Revisado: 23/11/2021 | Aceito: 26/11/2021 | Publicado: 08/12/2021

Laura Martins de Siqueira

ORCID: https://orcid.org/0000-0002-7687-093X Faculdade de Ciências da Saúde da Universidade do Vale do Paraíba, Brasil

E-mail: lau_sikers@hotmail.com

Gabriela Souza Silva

ORCID: https://orcid.org/0000-0003-4120-3763

Faculdade de Ciências da Saúde da Universidade do Vale do Paraíba, Brasil

E-mail: souzasilvagj@gmail.com

Catarina Agmar Machado e Souza

ORCID: https://orcid.org/0000-0001-8929-636X

Faculdade de Ciências da Saúde da Universidade do Vale do Paraíba, Brasil E-mail: catarina080@gmail.com

Maíza de Sousa Silva

ORCID: https://orcid.org/0000-0003-4175-6296

Faculdade de Ciências da Saúde da Universidade do Vale do Paraíba, Brasil E-mail: maiza_sousa10@outlook.com

Brunna Goulart

ORCID: https://orcid.org/0000-0001-6031-3496 Faculdade de Ciências da Saúde da Universidade do Vale do Paraíba, Brasil E-mail: brunna1d.goulart@gmail.com

Raíssa da Costa Furtado

ORCID: https://orcid.org/0000-0002-5660-7931 Faculdade de Ciências da Saúde da Universidade do Vale do Paraíba, Brasil E-mail: raissacfurtado@gmail.com

Antonieta Marques Caldeira Zabeu

ORCID: https://orcid.org/0000-0003-0138-2250

Faculdade de Ciências da Saúde da Universidade do Vale do Paraíba, Brasil E-mail: antonieta@univap.br

\begin{abstract}
Resumo
Transmitida pelo vírus da família Coronaviridae - e com origem no grupo II, onde também se encontra o coronavírus humano SARS-CoV-2 - a coronavirose bovina esta presente nas afecções do trato gastrointestinal e trato respiratório, causando diarreia neonatal e disenterias de inverno em bovinos adultos, associadas também a quadros de pneumonia. $\mathrm{O}$ coronavírus SARS-CoV-2 é um vírus originado na China no final do ano de 2019, agente etiológico da Covid-19, a qual afeta principalmente o trato respiratório inferior na população. Este trabalho tem por objetivo revisar a literatura científica e discorrer sobre as diferenças entre o coronavírus bovino e humano, realizando uma comparação inerente à profilaxia, tratamento, sintomas, diagnóstico, sistema imune e transmissão dos mesmos, com o objetivo de esclarecer tais peculiaridades mediante uma revisão bibliográfica relativa ao tema.
\end{abstract}

Palavras-chave: Coronavírus; BCoV; SARS-CoV-2; Bovinos; Humanos; Covid-19.

\begin{abstract}
Transmitted by the virus of the Coronaviridae family - and originating in group II, where the human coronavirus SARS$\mathrm{CoV}-2$ is also found - bovine coronavirus is present in diseases of the gastrointestinal tract and respiratory tract, causing neonatal diarrhea and winter dysentery in cattle adults, also associated with pneumonia. The SARS-CoV-2 coronavirus is a virus originated in China at the end of 2019, the etiologic agent of Covid-19, which mainly affects the lower respiratory tract in the population. This work aims to review the scientific literature and discuss the differences between bovine and human coronaviruses, making a comparison inherent to the prophylaxis, treatment, symptoms, diagnosis, immune system and transmission thereof, in order to clarify such peculiarities through a bibliographical review on the subject.
\end{abstract}

Keywords: Coronavirus; BCoV; SARS-CoV-2; Cattle; Humans; Covid-19.

\section{Resumen}

Transmitidos por elvirus de la família Coronaviridae - y conorigenenel grupo II, donde también se encuentra El coronavirus humano SARS-CoV-2 -loscoronavirus bovinos están presentes em afectos Del tracto gastrointestinal y Del tracto respiratorio, provocando diarrea neonatal y disentería invernal en bovinos adultos, también associados com neumonía. El coronavirus SARS-CoV-2 es um virus originado en China a finales de 2019, el agente etiológico del Covid-19, que afecta principalmente al tracto respiratorio inferior de lapoblación. Este artículo tiene como objetivo revisar la literatura científica 
y discutir las diferencias entre coronavirus bovino y humano, haciendo una comparacióninherente a laprofilaxis, tratamiento, síntomas, diagnóstico, sistema inmunológico y transmisión de losmismos, com elfin de esclarecer tales peculiaridades a través de una revisión bibliográfica sobre el tema.

Palabras clave: Coronavirus; BCoV; SARS-CoV-2; Vacas; Humanos; Covid-19.

\section{Introdução}

A coronavirose bovina $(\mathrm{BCoV})$ é uma doença viral transmitida pelo vírus da família Coronaviridae, do gênero Coronavírus, o qual é subdividido em três grupos, determinados pela diferenciação dos epítopos presentes nas glicoproteínas, estando ele incluso no grupo II onde também se inclui o coronavírus humano (SARS-CoV-2) (Suphoronski, Lorenzetti, Ribeiro, Medeiros, Pannunzio, Possati \& Alfieri, 2016; Nascimento, Melo, de Matos Santana, Melo, de Souza Correia, Bomfim \& Rizzo, 2020).

O BCoV é um vírus arredondado, seu tamanho varia entre 100 a 150 nanômetros de diâmetro e possui entre quatro e cinco proteínas estruturais que se projetam dele e dão o formato de uma coroa (do latim, corona). As proteínas M, Sm, HE, S e I, estão associadas às doenças das três classes do coronavírus, estando assim presentes nas comorbidades do trato gastrointestinal e trato respiratório, causando episódios de diarreia em bezerros/neonatos e disenterias em bovinos adultos, estando associados ainda a quadros respiratórios de pneumonia, peritonites e encefalites,sendo esse último quadro respiratório, comumente associado ao coronavírus humano (de Mello, Lorencena, Delai, Kunz, Possatti \& Takiuchi, 2016).

Dado o fato de que muitos são os possíveis agentes para as afecções do trato respiratório e este ser o tropismo relacionado ao BCoV, o teste necessário para detecção deste é o RT- PCR, pois de acordo com a literatura, é o que possui maior especificidade e demanda de pequena quantidade biológica amostral. Este teste possui sensibilidade alta e os primers foram desenhados utilizando sequências de genes atuais da coronavirose bovina, o que implica na base mais acurada para diagnósticos, tendo em vista a importância para saúde animal e para a saúde pública, uma vez que o teste PCR também é utilizado para diagnósticos em humanos, tendo apreciação de 86\% a 88\% para o coronavírus SARS-CoV-2 (Asano, Souza, Silva, Richtzenhain \& Brandão, 2009; Floriano, Silvinato, Bernardo, Reis \& Soledade, 2020).

O presente trabalho tem como propósito, apresentar os aspectos gerais de conformidade do coronavírus bovino (BCoV) e diferenciá-lo do coronavírus humano, tal como apontar os sintomas, as formas de contaminação, prevenção da doença e, ainda, as formas de detecção e diagnósticos de ambos os vírus, por meio de uma revisão literária realizada através de referências pesquisadas em plataformas digitais científicas acerca do assunto abordado.

\section{Metodologia}

Este artigo propõe realizar uma revisão bibliográfica sistemática, mediante uma pesquisa qualitativa e exploratória as quais têm em suma, evidenciar o contexto com o problema - referente ao coronavírus bovino (BCoV) e o coronavírus humano (SARS-CoV-2) e suas implicações à sanidade do rebanho e da população, partindo dos aspectos gerais da doença, bem como sintomas, transmissão, profilaxia, diagnóstico e tratamento, constituindo uma analogia entre ambos os vírus destacando as semelhanças e diferenças entre os mesmos (Bezerra, do Espírito Santo, Monteiro \& Muto, 2020). As buscas para fundamentação deste trabalho foram efetuadas através de referências em plataformas digitais científicas de dados indexados como, Google Acadêmico, PubMed e Scielo, utilizando os seguintes termos de busca Coronavírus, BCoV, SARS-CoV-2, Bovinos, Humanos e Covid-19, inerentes ao tema abordado, dentro do período do ano de 2009 a 2021, nos idiomas português, inglês e espanhol, com o objetivo de proporcionar maior conhecimento acerca das respectivas enfermidades, auxiliando na formulação de hipóteses, sendo os critérios de inclusão a etiologia, diagnóstico, transmissão e profilaxia de acordo com as palavras associadas descritas e sendo selecionados estudos em português e inglês com maior relevância referente ao assunto e como critério de exclusão, os artigos que não exibiram o objetivo colocado anteriormente e que não se apresentam nos idiomas inglês e português. 


\section{Resultados Discussão}

O resultado da atual pesquisa sistemática manifestou-se a respeito dos coronavírus tanto humano, quanto bovino, evidenciando suas particularidades entre si e especificando sintomas, diagnósticos, possíveis tratamentos e formas de transmissão. Foi encontrado um total de 1.180 artigos nas bases de dados livres, englobados no intervalo de tempo entre 2009 2021, dentre os quais foram escolhidos 25 para compor este artigo de revisão bibliográfica - os quais foram sumarizados no Quadro 1. a seguir, apresentando o nome do artigo, seu objetivo, metodologia e conclusão -, nos idiomas inglês e português, bem como os que continham os respectivos descritores Coronavírus, BCoV, SARS-CoV-2, Bovinos, Humanos e Covid-19, relatando um tema de grande importância social de maneira plausível, visto que muitas dúvidas ainda se fazem presentes no cotidiano brasileiro, como por exemplo, em saber se o SARS-CoV-2 é transmissível ou não para os bovinos e se o BCoV é transmissível para os humanos, visando à sanidade do rebanho e também do trabalhador.

Quadro 1. Descrição dos artigos selecionados, contendo os objetivos, metodologia, e conclusão das literaturas consideradas.

\begin{tabular}{|c|c|c|c|c|}
\hline & Artigo & Objetivo & Metodologia & Conclusão \\
\hline 1 & $\begin{array}{l}\text { Andrade \& Moraes (2020). } \\
\text { O que o Coronavírus tem nos } \\
\text { tirado? Anos potenciais de } \\
\text { vida perdidos em Minas } \\
\text { Gerais/ What has the } \\
\text { Coronavirus take from us? } \\
\text { Potential years of life lost in } \\
\text { Minas Gerais. }\end{array}$ & $\begin{array}{l}\text { Caracterizar o impacto } \\
\text { social das mortes por } \\
\text { coronavírus em decorrência } \\
\text { dos anos de vida perdidos } \\
\text { no Estado de Minas Gerais. }\end{array}$ & $\begin{array}{l}\text { Utilização de estudos de caráter } \\
\text { qualitativo com dados } \\
\text { quantitativos e descritivos à } \\
\text { respeito das mortes por } \\
\text { coronavírus em Minas Gerais até } \\
10 \text { de junho de } 2020 .\end{array}$ & $\begin{array}{l}\text { Faz-se menção às consequências } \\
\text { devastadoras das mortes por Covid-19 à } \\
\text { sociedade, que além de impactar a saúde } \\
\text { pública, impacta na falta de mão de obra para } \\
\text { o mercado. }\end{array}$ \\
\hline 2 & $\begin{array}{l}\text { Arenas, et al. (2021). } \\
\text { Bovine Coronavirus Immune } \\
\text { Milk Against Covid-19. }\end{array}$ & $\begin{array}{l}\text { Estudar a eficácia do } \\
\text { consumo de leite bovino de } \\
\text { vacas imunizadas contra o } \\
\text { BCoV, como terapia } \\
\text { imunoestimulante para o } \\
\text { ser humano, visando o } \\
\text { controle do SARS-CoV-2. }\end{array}$ & $\begin{array}{l}\text { Estudo de caráter qualitativo e } \\
\text { quantitativo; Buscam informações } \\
\text { e métodos para reforçar a } \\
\text { imunidade humana contra o } \\
\text { SARS-CoV-2. }\end{array}$ & $\begin{array}{l}\text { Concluem que o leite cru e pasteurizado } \\
\text { podem conter anticorpos específicos contra } \\
\text { diferente patógenos humanos, sendo a IgG } \\
\text { bovina funcionalmente ativa no trato } \\
\text { gastrointestinal humano, prevenindo também } \\
\text { infecções do trato respiratório. }\end{array}$ \\
\hline 3 & $\begin{array}{l}\text { Asano, et al. (2009). } \\
\text { Detecção rápida do } \\
\text { Coronavírus } \\
\text { por meio de uma semi-nested } \\
\text { RT-PCR. }\end{array}$ & $\begin{array}{l}\text { Testar o protocolo de PCR } \\
\mathrm{N} \text { para detecção rápida do } \\
\mathrm{BCoV} \text {, a partir das } \\
\text { amostras fecais, fazendo o } \\
\text { estudo da sequência gênica } \\
\text { dos nucleocapsídeos. }\end{array}$ & $\begin{array}{l}\text { Foram utilizados primers com a } \\
\text { região do nucleocapsídeos } \\
\text { conservado, foram estudadas as } \\
\text { temperaturas de recozimento, } \\
\text { analisadas as sequências gênicas e } \\
\text { comparadas entre o PCR- semi } \\
\text { aninhado e o PCR aninhado. }\end{array}$ & $\begin{array}{l}\text { O RT-PCR rápido foi padronizado como } \\
\text { referência na detecção do } \mathrm{BCoV} \text { em caso } \\
\text { pela alta sensibilidade analítica, baixo custo e } \\
\text { baixa interferência de inibidores. }\end{array}$ \\
\hline 4 & $\begin{array}{l}\text { Barry, et al. (2009). } \\
\text { Bovine coronavirus detection } \\
\text { in a collection of diarrheic } \\
\text { stool samples positive for } \\
\text { group a bovine rotavirus. }\end{array}$ & $\begin{array}{l}\text { Avaliar a frequência da } \\
\text { infecção simultânea das } \\
\text { doenças entéricas GARV e } \\
\text { BCoV }\end{array}$ & $\begin{array}{l}\text { Amostras de fezes diarreicas } \\
\text { coletadas de bezerros que já } \\
\text { haviam sido diagnosticados com } \\
\text { o rotavírus, foram conservadas, } \\
\text { tiveram seu RNA extraído e feito } \\
\text { o RT-PCR para análise. }\end{array}$ & $\begin{array}{l}\text { O resultado positivo na detecção de } \mathrm{BCoV} \\
\text { nas amostras, enfatizou que a infecção } \\
\text { simultânea por ambos os vírus é frequente } \\
\text { nos bezerros. }\end{array}$ \\
\hline 5 & $\begin{array}{l}\text { Bastianello, et al. (2020). } \\
\text { Diferenças do coronavírus } \\
\text { entre espécies. }\end{array}$ & $\begin{array}{l}\text { Explorar as diferenças e } \\
\text { apontar as informações } \\
\text { sobre as principais } \\
\text { diferenças dentre } \quad \text { o } \\
\text { coronavírus humano e } 0 \\
\text { animal. }\end{array}$ & $\begin{array}{l}\text { Revisão bibliográfica de caráter } \\
\text { qualitativo. }\end{array}$ & $\begin{array}{l}\text { Não existe a transmissão direta entre as } \\
\text { espécies, porém o cuidado se deve ao animal } \\
\text { de um vetor mecânico da doença para } \\
\text { superfícies. }\end{array}$ \\
\hline
\end{tabular}




\begin{tabular}{|c|c|c|c|c|}
\hline 6 & $\begin{array}{l}\text { Bezerra Jr, et al. (2009). } \\
\text { Surto de diarreia em vacas de } \\
\text { um rebanho leiteiro na região } \\
\text { sul de Minas Gerais: detecção } \\
\text { de coronavírus bovino nas } \\
\text { fezes. }\end{array}$ & $\begin{array}{l}\text { A pesquisa buscou } \\
\text { apresentar os aspectos } \\
\text { epidemiológicos e clínicos } \\
\text { do surto de diarreia bovina } \\
\text { em uma propriedade em } \\
\text { Lavras. }\end{array}$ & $\begin{array}{l}\text { Uma pesquisa a campo foi feita } \\
\text { junto ao proprietário para coleta } \\
\text { de dados clínicos e } \\
\text { epidemiológicos das fezes de } \\
\text { bovinos, em uma propriedade no } \\
\text { Estado de Minas Gerais, durante } \\
\text { o surto da diarreia. }\end{array}$ & $\begin{array}{l}\text { O impacto econômico na pecuária de Minas } \\
\text { Gerais pode ser bastante afetado com essa } \\
\text { doença, considerando as crises analisadas } \\
\text { similarmente. Contudo é necessário pontuar } \\
\text { doenças que causam a diarreia em bovinos } \\
\text { adultos. }\end{array}$ \\
\hline 8 & $\begin{array}{l}\text { Cagnini et al. (2015). } \\
\text { Estudo histopatológico, imuno- } \\
\text { histoquímico e molecular da } \\
\text { infecção por BHV-5 no } \\
\text { sistema nervoso central de } \\
\text { bovinos experimentalmente } \\
\text { infectados. }\end{array}$ & $\begin{array}{l}\text { Fazer a descrição da } \\
\text { distribuição e gravidade das } \\
\text { alterações no SNC de } \\
\text { bezerros infectados com } \\
\text { BHV-5 e fazer a } \\
\text { comparação com dessas } \\
\text { alterações com os } \\
\text { resultados do PCR e IHQ. }\end{array}$ & $\begin{array}{l}\text { Coleta de amostras, com exame } \\
\text { histopatológico e imuno- } \\
\text { histoquímico a partir da isolação } \\
\text { do DNA para a análise das } \\
\text { sequências e estatísticas. }\end{array}$ & $\begin{array}{l}\text { Animais com sinais de problemas } \\
\text { neurológicos são mais susceptíveis a testar } \\
\text { positivo para o PCR e o IHC. O telencéfalo é } \\
\text { o local mais adequado para firmar o } \\
\text { diagnóstico do BHV-5. }\end{array}$ \\
\hline 9 & $\begin{array}{l}\text { Coura, F. M. (2011). } \\
\text { Estudo longitudinal } \\
\text { prospectivo da incidência de } \\
\text { enteropatógenos em bezerras } \\
\text { em uma propriedade leiteira. }\end{array}$ & $\begin{array}{l}\text { Fazer a descrição dos casos } \\
\text { de rotavírus, coronavírus } \\
\text { bovino, salmonela e } \\
\text { escherichia coli, por meio } \\
\text { de um estudo } \\
\text { observacional. }\end{array}$ & $\begin{array}{l}\text { Estudo qualitativo a partir de } \\
\text { amostras fecais de } 67 \text { bezerras } \\
\text { leiteiras no município de } \\
\text { Martinho Campos em Minas } \\
\text { Gerais. }\end{array}$ & $\begin{array}{l}\text { Foi concluído que a incidência de diarreia é } \\
\text { maior nas duas primeiras semanas de vida, } \\
\text { de rotavírus nas três primeiras, e que foram } \\
\text { identificados em amostras decais e diarreicas } \\
\text { e apenas a primeira pode ser associada à } \\
\text { doença. }\end{array}$ \\
\hline 10 & $\begin{array}{l}\text { Cruvinel, et al. (2010). } \\
\text { Sistema imunitário: Parte I. } \\
\text { Fundamentos da imunidade } \\
\text { inata com ênfase nos } \\
\text { mecanismos moleculares e } \\
\text { celulares da resposta } \\
\text { inflamatória. }\end{array}$ & $\begin{array}{l}\text { Revisar e fundamentar a } \\
\text { imunidade inata com ênfase } \\
\text { nos } \\
\text { moleculares e } \quad \text { celulares } \\
\text { perante a } r \text { resposta } \\
\text { inflamatória. }\end{array}$ & $\begin{array}{l}\text { Revisão bibliográfica de caráter } \\
\text { qualitativo. }\end{array}$ & $\begin{array}{l}\text { O sistema imunológico é constituído por uma } \\
\text { intrincada rede de órgãos, células e } \\
\text { moléculas, e tem por finalidade manter a } \\
\text { homeostase do organismo, combatendo as } \\
\text { agressões em geral. Seus mecanismos } \\
\text { compreendem barreiras físicas, químicas e } \\
\text { biológicas, componentes celulares e } \\
\text { moléculas solúveis. A revisão tem como } \\
\text { objetivo resgatar os fundamentos dessa } \\
\text { resposta, que apresenta elevada } \\
\text { complexidade e é constituída por diversos } \\
\text { componentes articulados que convergem } \\
\text { para a elaboração da resposta imune } \\
\text { adaptativa. }\end{array}$ \\
\hline 11 & $\begin{array}{l}\text { de Mello, et al. (2016). } \\
\text { Detecção do coronavírus } \\
\text { bovino em bezerros com } \\
\text { doença respiratória no } \\
\text { município de Ouro Verde do } \\
\text { Oeste-Paraná. }\end{array}$ & $\begin{array}{l}\text { Investigar a ocorrência do } \\
\text { BCoV em secreções nasais } \\
\text { de bezerros provenientes de } \\
\text { rebanhos com problemas } \\
\text { respiratórios utilizando a } \\
\text { técnica RT-PCR. }\end{array}$ & $\begin{array}{l}\text { A técnica de Semi-nested PCR } \\
\text { para a amplificação parcial do } \\
\text { gene } \mathrm{N} \text { do } \mathrm{BCoV} \text { foi utilizada de } \\
\text { acordo com metodologia descrita } \\
\text { por Alfieri et al., com tamanhos } \\
\text { esperados de } 454 \mathrm{pb} \text { e } 251 \mathrm{pb} \text { no } \\
\text { primeiro e segundo round de } \\
\text { amplificação, respectivamente. } \\
\text { Para validação do teste foram } \\
\text { incluídos em todos os } \\
\text { procedimentos de extração e } \\
\text { amplificação, um controle } \\
\text { negativo e um controle positivo. }\end{array}$ & $\begin{array}{l}\text { Os resultados demonstram a circulação do } \\
\text { BCoV em rebanhos bovinos no Paraná com } \\
\text { problemas respiratórios e a aplicabilidade da } \\
\text { técnica Semi-nested PCR para o diagnóstico } \\
\text { conclusivo. }\end{array}$ \\
\hline
\end{tabular}




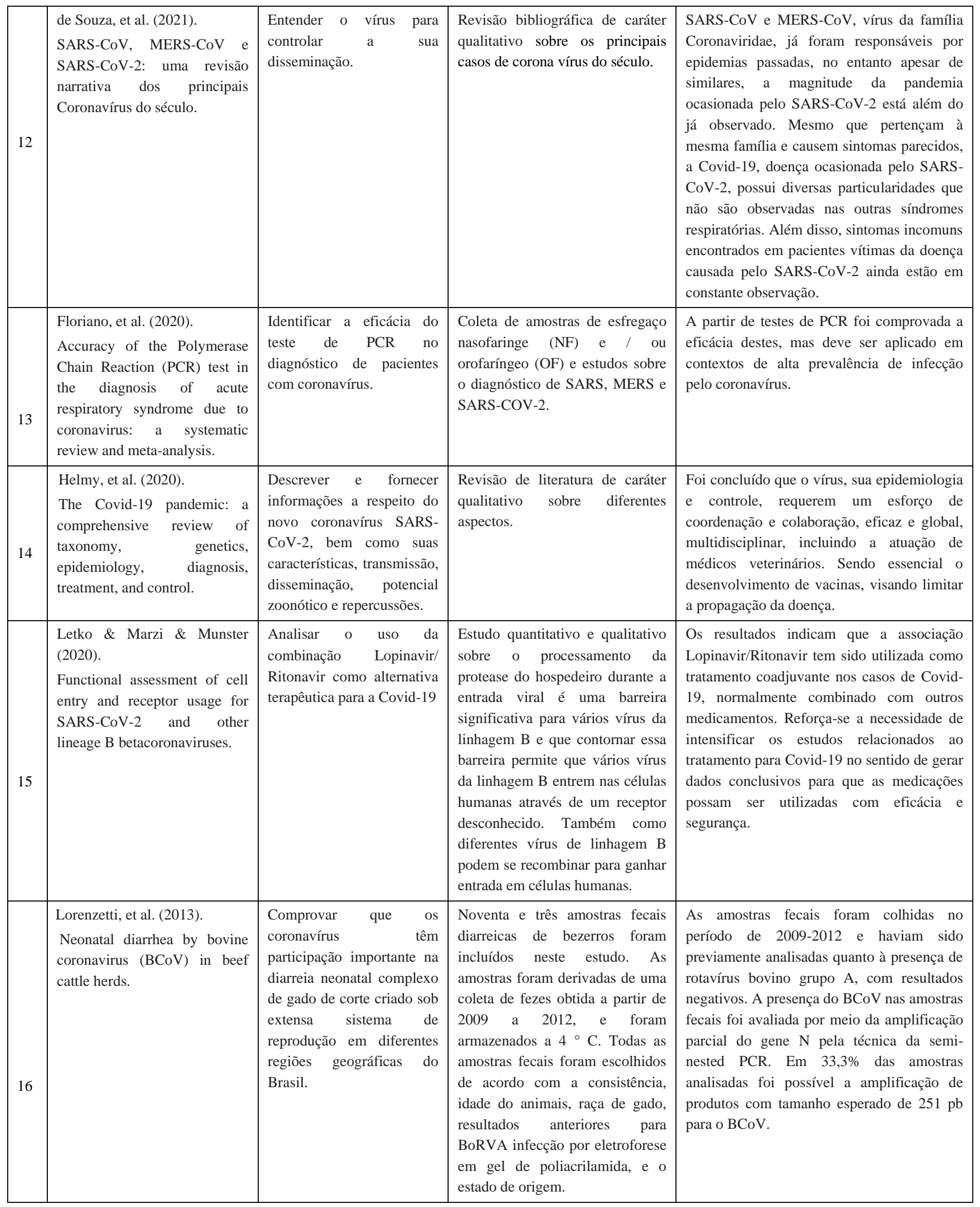




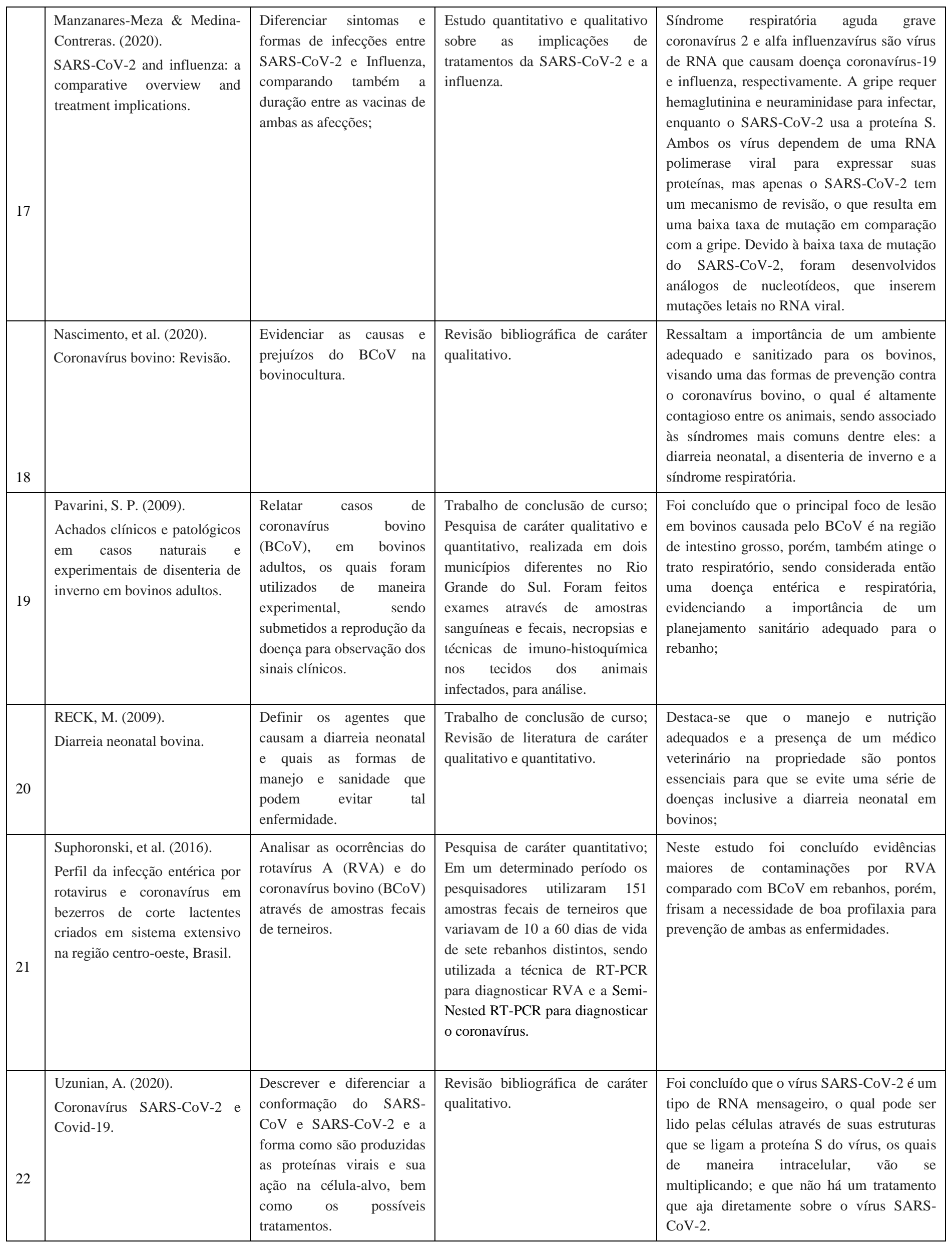




\begin{tabular}{|c|c|c|c|c|}
\hline 23 & $\begin{array}{l}\text { Van Doremalen, et al. (2020). } \\
\text { Aerosol and surface stability of } \\
\text { SARS-CoV-2 as compared } \\
\text { with SARS-CoV-1. }\end{array}$ & $\begin{array}{l}\text { Comparar o SARS-CoV-2 } \\
\text { e o SARS-CoV-1 em } \\
\text { relação à estabilidade viral } \\
\text { em aerossol em diversas } \\
\text { superfícies e as taxas de } \\
\text { decaimento. }\end{array}$ & $\begin{array}{l}\text { Revisão bibliográfica de caráter } \\
\text { qualitativo e quantitativo; Para os } \\
\text { testes de taxa de decaimento, } \\
\text { utilizaram um teste de regressão } \\
\text { Bayesiana; }\end{array}$ & $\begin{array}{l}\text { Concluiu-se que a estabilidade de ambos os } \\
\text { vírus são semelhantes, indicando que as } \\
\text { diferenças entre eles ocorrem por meio de } \\
\text { outros fatores }\end{array}$ \\
\hline 24 & $\begin{array}{l}\text { Vargas Júnior, S. F. (2015). } \\
\text { Diarreia em bezerros na região } \\
\text { sul do Rio Grande do Sul. }\end{array}$ & $\begin{array}{l}\text { Descrever as principais } \\
\text { causas de diarreia em } \\
\text { bezerros; }\end{array}$ & $\begin{array}{l}\text { Dissertação para conclusão de } \\
\text { curso; Foram diagnosticados } 94 \\
\text { bezerros com diarreia, fizeram a } \\
\text { análise por meio de amostras } \\
\text { fecais para descobrir a causa. }\end{array}$ & $\begin{array}{l}\text { As diarreias foram diagnosticadas de maior } \\
\text { prevalência por causas parasitárias e } \\
\text { bacterianas; Ressaltam a importância de um } \\
\text { manejo adequado, visando às condições } \\
\text { sanitárias do local onde o rebanho } \\
\text { permanece. }\end{array}$ \\
\hline 25 & $\begin{array}{l}\text { Vieira \& Emery \& Andriolo } \\
(2020) \text {. } \\
\text { Covid-19: laboratory diagnosis } \\
\text { for clinicians. } \\
\text { Anupdatingarticle. }\end{array}$ & $\begin{array}{l}\text { Definir coronavírus, sua } \\
\text { origem, ação e causas } \\
\text { mantendo a ênfase no } \\
\text { Covid-19; }\end{array}$ & $\begin{array}{l}\text { Revisão bibliográfica de caráter } \\
\text { qualitativo e quantitativo }\end{array}$ & $\begin{array}{l}\text { É de fundamental importância conhecer a } \\
\text { variabilidade do vírus, sabendo que dentre o } \\
\text { período de contaminação e teste diagnóstico } \\
\text { ele pode evoluir. }\end{array}$ \\
\hline
\end{tabular}

Fonte: Autores.

\section{Discussão}

$\mathrm{O}$ BCoV é o segundo agente viral mais comum associado com a diarreia em bezerros. Além do imprescindível manejo correto - boa nutrição, higiene em todas as instalações, separação dos animais enfermos e quarentena de animais recémadquiridos ou enfermos, com o intuito de conter a contaminação viral - há possibilidade para que os animais sejam imunizados também. Atualmente há vacinas administradas via intranasal em bezerros de três a quatro dias a fim de imunizar os neonatos. Com a alta taxa de contaminação em bezerros com menos de três semanas de vida, uma das formas de imunidade vem da forma passiva, ou seja, com a infecção e a vacinação da mãe, o colostro oferecido será rico em imunoglobulinas (Lorenzetti, Arruda Leme, Ribeiro, De Souza, Alfieri \& Alfieri, 2013). Um dos meios de profilaxia é a vacinação das vacas secas entre três a seis semanas antes do parto, com o vírus inativo; quatro semanas após ser aplicada a primeira dose, antes do parto, deve ocorrer a reaplicação vacinal. Desta forma, com a progenitora imunizada, ao alimentar o filhote, ele também será imunizado por meio da ingestão do colostro (Nascimento, et al., 2020).

Coincidente à Organização Mundial da Saúde (OMS), caso o novo coronavírus SARS-CoV-2, nomeado Covid-19, estiver se propagando em alguma comunidade, alguns passos simples terão de ser tomados tanto pela população, quanto pelo governo, através de distanciamento físico com distância aproximada de 2 metros, uso de máscara, manutenção de locais bem ventilados, evitando multidões, higiene das mãos e tossir entre o braço e antebraço ou em um lenço de papel dobrado, evitando desta forma, a disseminação do agente etiológico.Na medicina humana as tão esperadas vacinas contra esta enfermidade - as quais têm sido manipuladas como a principal forma de profilaxia visando à erradicação da virulência - foram desenvolvidas por três métodos diferentes: O primeiro é pegar o vírus que carrega a moléstia, ou um muito semelhante a ele, e inativá-lo ou matá-lo por intermédio de produtos químicos, calor ou radiação. A segunda maneira é uma vacina com um vírus vivo atenuado, ou seja, uma versão viva, porém, enfraquecida. E a terceira, é a vacina de vetor viral, a qual utiliza uma forma de imunização através de um vírus seguro,entregando subpartes específicas - denominadas proteínas - do germe de interesse para que possa desencadear uma resposta imunológica sem provocar a doença (Andrade \& Moraes, 2020).

Sendo a diarreia neonatal uma das principais preocupações na infecção pelo $\mathrm{BCoV}$, o tratamento necessário exige que o método seja preventivo contra doenças onde os agentes infecciosos são vírus, nos quais se encaixam o coronavírus e o rotavírus. Por conta disso, a ferramenta apontada por Reck (2009), é vista como fundamental para este tratamento, sendo a prevenção, a ingestão de colostro que oferece nutriente e imunoglobulinas essenciais para os terneiros. Como terapias de suporte, o produtor deve também, isolar os animais infectados para que a doença não se alastre pelo rebanho, e prosseguir com 
os cuidados que incluem a hidratação - de forma endovenosa uma vez que as células intestinais estão lesionadas e não são absortivas -, aplicação de antibióticos para as infecções secundárias à coronavirose, alimentação nutritiva e balanceada, impedindo o agravamento da doença (Nascimento, et al., 2020).

Tendo em vista que o SARS-CoV-2 é um vírus de relevância mundial e ainda com foco atual da saúde pública, muitos trabalhos atuais têm buscado respostas para esse tratamento, o qual ainda não possui especificidade, apenas a busca pelo reforço do sistema imunológico tanto humano, quanto animal (Andrade \& Moraes, 2020).

Como cita Arenas et al. (2021), o coronavírus que infecta os humanos está no mesmo grupo sorológico que o coronavírus bovino, pois ambos possuem a mesma característica de nucleotídeos nos genes, isso gerou a proposta de seu trabalho, com o uso de imunidade passiva heteróloga a partir do leite bovino já imunizado como complemento para auxiliar a defesa do sistema imunológico intestinal. Seu trabalho ainda está em desenvolvimento, porém, a proposta se sustenta de acordo com a nutritiva carga imunológica do colostro e o seu desempenho na saúde humana.

Em geral, o BCoV pode gerar três distúrbios nos animais acometidos por ele, sendo a disenteria de inverno, a diarreia neonatal e afecção das vias respiratórias. A primeira, disenteria de inverno, é uma importante doença infectocontagiosa que acomete o gado adulto em estações de baixa temperatura do ano, com maior predomínio em vacas leiteiras causando diarreia aguda severa, podendo apresentar muco e/ou sangue, cólicas leves, anorexia, perda de apetite, corrimento nasolacrimal mucoso com estrias de fibrinas e tosse (Bezerra, Brandão, Pavarini, Varaschin, Wouters, Villarreal \& Costa, 2009). Diante de tais alterações, os animais acometidos podem apresentar perda de peso e desidratação levando a uma queda na produção leiteira. A diarreia neonatal caracteriza-se pelo aspecto líquido e abundante em terneiros, podendo haver vestígios de sangue, ocasionado pela hemorragia intestinal e desidratação, podendo evoluir para uma hipovolemia em poucas horas após o início dos sinais clínicos, resultando no óbito do animal. Já as síndromes respiratórias, atingem bovinos de todas as idades, podendo ser identificada em amostras de fezes, secreções nasais e pulmonares de animais em recuperação devido a uma pneumonia. Geralmente, a síndrome respiratória ocorre em animais com sistema imune deprimido ou em bezerros que não receberam o colostro, podendo causar broncopneumonia (Barry, Alfieri, Stipp \& Alfieri, 2009), com alto risco de fatalidade em animais longevos. Os sintomas clínicos podem variar diante do estado de gravidade do animal, podendo apresentar tosse, febre, perda de apetite, traqueíte, descarga nasal serosa e mucopurulenta e diarreia (Nascimento, et al., 2020).

Já o coronavírus SARS-CoV-2, o qual o mundo presencia nos últimos tempos, pode provocar sintomas diferenciados, pois esse vírus atinge diretamente o sistema respiratório, eventualmente evoluindo para um quadro de pneumonia atípica, além de possíveis insuficiências cardíacas graves e falência dos órgãos em 5 a 10\% dos casos (de Souza, da Silva, da Silva Pinheiro \& dos Santos, 2021) e apesar dos sintomas, algumas pessoas se mostraram positivas para o vírus SARS-CoV-2 (Covid-19), porém, não apresentando sintomas, ou seja, assintomáticos.

$\mathrm{O}$ diagnóstico do $\mathrm{BCoV}$ é realizado através de análises laboratoriais de fluidos corporais de animais infectados, principalmente fezes e secreções nasais, contudo, o diagnóstico pode ser prejudicado ou inviabilizado pelo curto período de eliminação viral característico de infecções agudas, da mesma forma nos casos subclínicos, o qual está relacionado aos animais que mesmo infectados, não apresentam manifestações ou sintomas detectáveis da doença (Pavarini, 2009). As técnicas predominantemente utilizadas para detecção do vírus são a microscopia eletrônica; imunofluorescência direta; imunohistoquímica; ensaio imunoenzimático (ELISA); hemaglutinação (HA) / inibição da hemaglutinação (HI); transcriptase reversa seguida pela reação em cadeia da polimerase (RT-PCR) e isolamento viral (Barry, et al., 2009).

Dentre estas opções diagnósticas, destaca-se o teste RT-PCR, pois o mesmo apresenta maior especificidade e sensibilidade na percepção de coronaviroses, podendo identificar a presença do vírus mesmo em fases de baixa eliminação viral, como no início ou final da infecção, impossibilitando falsos diagnósticos (Cagnini, Cunha, Pantoja, Badial, Oliveira-Filho, AraújoJunior \& Borges, 2015). 
O SARS-CoV-2 por sua vez, pode ser identificado através de exames moleculares, como o teste RT-PCR, o qual permite a identificação do RNA viral através de amostras de secreções do trato respiratório, sendo atualmente, o método mais utilizado e seguro para a detecção do Covid-19.

Entretanto, sua sensibilidade pode ser prejudicada por fatores como fase da infecção e carga viral, local da coleta (trato respiratório inferior ou superior), transporte e armazenamento das amostras (Veira, Emery \& Andriolo, 2020). Outro método diagnóstico são os exames imunológicos, os quais através de sangue capilar, sangue total, soro ou plasma, buscam identificar a presença de anticorpos específicos contra determinantes antigênicos do SARS-CoV-2, que por ser uma infecção viral, o organismo infectado produz anticorpos como reação protetora, principalmente imunoglobulinas A, M e G (IgA, IgM e IgG). O teste de ELISA e o Point-of-caretesting (POCT) são os mais utilizados nessa metodologia, havendo também os testes rápidos realizados através de material colhido das narinas e garganta para pesquisa de antígeno viral, porém, ainda existem poucos estudos quanto a sua efetividade (Andrade \& Moraes, 2020). Os vírus RNA, como por exemplo, os coronavírus, ao passar por mudanças ambientais ou climáticas estão passíveis de sofrer mutações espontâneas, podendo interferir na análise e no posterior diagnóstico, sendo assim, a coleta e o armazenamento de amostras devem ser executados de forma precisa (Bezerra, et al., 2009).

A entrada do $\mathrm{BCoV}$ no organismo do animal é dependente de uma das cinco proteínas presentes na sua dupla camada de lipídeos, proteína espícula $(\mathrm{S})$, proteína transmembrana $(\mathrm{M})$, proteína da nucleocápside $(\mathrm{N})$, proteína hemaglutinina-esterase (HE) e proteína envelope (E). A Proteína S é a principal proteína presente na estrutura do envelope e a mais polimórfica dos coronavírus, possuindo atividade hemaglutinante, sendo o principal alvo dos anticorpos neutralizantes (Uzunian, 2020).

Este vírus infecta as células epiteliais absortivas, principalmente no jejuno distal e íleo, afetando também as células das superfícies e das criptas do intestino grosso. A replicação viral ocorrerá no citoplasma da célula hospedeira, para isso, é necessário que a proteína HE se ligue ao ácido 9-O-acetil neuramínico e após a ligação com o receptor específico o vírus adentra a célula em um processo dependente da proteína $S$, o qual é responsável pela união do envelope viral e pela membrana celular (Letko, Marzi \& Munster, 2020).

As células infectadas manifestarão peptídeos virais em cima da sequência de aminoácidos do MHC-I. O sistema imune inato reconhece as estruturas moleculares produzidas pelos patógenos microbianos, as quais são denominadas Padrões Moleculares Associados ao Patógeno (PAMP’s) (Cruvinel, Mesquita Júnior, Araújo, Catelan, Souza, Silva \& Andrade, 2010). Assim como o BCoV bovino, o SARS-CoV-2 pertence ao gênero Betacoronavirus, possuindo proteínas estruturais S, E, M e N, além de pelo menos seis proteínas acessórias (Helmy, Fawzy, Elaswad,Sobieh, Kenney \& Shehata, 2020). O Seu RNA genômico possui aproximadamente $30 \mathrm{~kb}$, diferente do $\mathrm{BCoV}$ que possui $32 \mathrm{~kb}$. A replicação do coronavírus humano tem início na etapa de adsorção, quando a região de RBD da subunidade S1 da glicoproteína viral S interage com receptores de membrana celular da célula hospedeira, existindovariabilidade entre as espécies de coronavírus em relação aos receptores, alguns utilizam receptor aminopeptidase (APN), já o MERS-CoV, interage com o receptor Dipeptidil Peptidase (DPP4), enquanto o SARS-COV e o SARS-CoV-2 ligam-se ao receptor ACE na região RBD da glicoproteína S, possuindo uma afinidade de 10 a 20 vezes maior com o receptor ACE2 do que com a de SARS-CoV (Manzanares-Meza \& Medina-Contreras, 2020). Cepas distintas de coronavírus afetam diferentes espécies e sistemas específicos, visto que células respiratórias possuem moléculas de superfície diferentes das células intestinais.

Tal afecção provoca sintomas distintos respectivos a cada espécie, porém, de acordo com Bastianello et al. (2020), a transmissão direta entre espécies diferentes ainda não foi totalmente comprovada, entretanto, animais podem servir como vetores mecânicos devido ao contato dos mesmos com superfícies contaminadas.

Dentre as espécies humanas e bovinas, os respectivos coronavírus possuem maneiras de disseminações semelhantes entre si.Entre os bovinos, a transmissão ocorre por via oral ou aerossóis e há diversos fatores que contribuem para a contaminação, 
como por exemplo, a ingestão de vírus presente no ambiente contaminado por fezes, lembrando que terneiros assintomáticos também podem excretar o vírus em seus dejetos, atingindo principalmente animais com até três semanas de idade, com o pico de incidência aos seis dias, mas pode acometer também animais adultos, havendo contaminação através da utilização de comedouros e bebedouros infectados presentes no ambiente em que coabitam (Coura, 2011; Vargas Júnior, 2015). Já a transmissão do SARS-CoV-2 - coronavírus humano - ocorre primeiramente por uma pessoa eivada, seja ela sintomática, présintomática ou assintomática, mediante partículas virais abarcadas em gotículas de saliva ou gotículas advindas das narinas, expelidas durante espirros, tosse ou fala (aerossol).

A contaminação ocorre mediante inalação e, no caso das partículas depositadas através do manuseio de superfícies contaminadas e subsequente contato com olhos e boca e demais mucosas (Van Doremalen, Bushmaker, Morris, Holbrook, Gamble, Williamson \& Munster, 2020). Posto isto, evidencia-se que ambas as espécies necessitam de medidas profiláticas, conforme citado neste estudo anteriormente, para desta forma, preservar a higidez, dificultando contaminações virais entre indivíduos do mesmo gênero.

\section{Conclusão}

Em virtude dos fatos mencionados, compreende-se que o coronavírus bovino (BCoV) afeta diretamente a sanidade de rebanhos e a economia inerente ao mesmo, visto que, caso não seja tratado e adotadas as devidas medidas profiláticas, pode resultar em números de óbitos relevantes, principalmente de bezerros/neonatos afetados pela diarreia neonatal. Em relação ao SARS-CoV-2, o qual afetou e ainda afeta o mundo causando diversos óbitos, é preciso manter as orientações da Organização Mundial da Saúde (OMS), principalmente a administração das devidas vacinas e suas respectivas doses. Por conseguinte, é de extrema importância a disseminação de informações acerca do tema a fỉm de evitar a disseminação da doença e o possível surgimento de novas variantes do vírus.

Trabalhos futuros de análise e compreensão da doença nas espécies acometidas por este grupo viral; e entre as espécies também; serão importantes na busca de técnicas de diagnóstico precoce e tratamentos cada vez mais assertivos e eficientes, a fim de evitar as perdas econômicas quando falamos do acometimento de bovinos e da perda de vidas humanas como se viu durante a pandemia.

\section{Referências}

Andrade, J. V., \& Moraes, R. C. C. (2020). O que o Coronavírus tem nos tirado? Anos potenciais de vida perdidos em Minas Gerais/What has the Coronavirus take from us? Potential years of life lost in Minas Gerais. Journal of Nursing and Health, 10(4).

Arenas, A., Borge, C., Carbonero, A., Garcia-Bocanegra, I., Cano-Terriza, D., Caballero, J., \& Arenas-Montes, A. (2021). Bovine Coronavirus Immune Milk Against COVID-19. Frontiers in Immunology, 12, 843.

Asano, K. M., Souza, S. P., Silva, S. O., Richtzenhain, L. J., \& Brandão, P. E. (2009). Detecção rápida do Coronavírus Bovino (BCoV) por meio de uma seminested RT-PCR. Pesquisa Veterinária Brasileira, 29(11), 869-873.

Barry, A. F., Alfieri, A. F., Stipp, D. T., \& Alfieri, A. A. (2009). Bovine coronavirus detection in a collection of diarrheic stool samples positive for group a bovine rotavirus. Brazilian Archives of Biology and Technology, 52, 45-49.

Bastianello, H. C., Cabral, V. X., da Silva, L. G. P., \& Risch, A. L. C. (2020). Diferenças do coronavírus entre espécies. anais congrega MIC-ISBN: 978-6586471-05-2 e ANAIS MIC JR.-ISBN: 978-65-86471-06-9, 16, 157-161.

Bezerra Jr, P. S., Brandão, P. E., Pavarini, S. P., Varaschin, M. S., Wouters, F., Villarreal, L. Y. B., ... \& Costa, G. M. (2009). Surto de diarreia em vacas de um rebanho leiteiro na região sul de Minas Gerais: detecção de coronavírus bovino nas fezes. Arquivo Brasileiro de Medicina Veterinária e Zootecnia, 61, 992-995.

Bezerra, D. R. C., do Espírito Santo, F. H., Monteiro, J. K. D. M. F., \& Muto, T. S. (2020). Os vulneráveis no período do COVID-19: uma revisão integrativa de literatura. Research, Society and Development, 9(10), e4699108860-e4699108860.

Cagnini, D. Q., Cunha, P. H., Pantoja, J. C., Badial, P. R., Oliveira-Filho, J. P. D., Araújo-Junior, J. P., ... \& Borges, A. S. (2015). Estudo histopatológico, imuno-histoquímico e molecular da infecção por BHV-5 no sistema nervoso central de bovinos experimentalmente infectados. Pesquisa Veterinária Brasileira, 35(4), 337-343. 
Coura, F. M. (2011). Estudo longitudinal prospectivo da incidência de enteropatógenos em bezerras em uma propriedade leiteira.

Cruvinel, W. D. M., Mesquita Júnior, D., Araújo, J. A. P., Catelan, T. T. T., Souza, A. W. S. D., Silva, N. P. D., \& Andrade, L. E. C. (2010). Sistema imunitário: Parte I. Fundamentos da imunidade inata com ênfase nos mecanismos moleculares e celulares da resposta inflamatória. Revista Brasileira de Reumatologia, 50, 434-447.

Mello, J. L., Lorencena, D., Delai, R. R., Kunz, A. F., Possatti, F., \& Takiuchi, E. (2016). Detecção do coronavírus bovino em bezerros com doença respiratória no município de ouro verde do oeste-paraná. Revista de Ciência Veterinária e Saúde Pública, 3, $174-176$.

Souza, L. C., da Silva, T. O., da Silva Pinheiro, A. R., \& dos Santos, F. D. S. (2021). SARS-CoV, MERS-CoV e SARS-CoV-2: uma revisão narrativa dos principais Coronavírus do século. Brazilian Journal of Health Review, 4(1), 1419-1439.

Floriano, I., Silvinato, A., Bernardo, W. M., Reis, J. C., \& Soledade, G. (2020). Accuracy of the Polymerase Chain Reaction (PCR) test in the diagnosis of acute respiratory syndrome due to coronavirus: a systematic review and meta-analysis. Revista da Associação Médica Brasileira, $66,880-888$.

Helmy, Y. A., Fawzy, M., Elaswad, A., Sobieh, A., Kenney, S. P., \& Shehata, A. A. (2020). The COVID-19 pandemic: a comprehensive review of taxonomy, genetics, epidemiology, diagnosis, treatment, and control. Journal of clinical medicine, 9(4), 1225.

Letko, M.; Marzi, A.; Munster, V. Functional assessment of cell entry and receptor usage for SARS-CoV-2 and other lineage B betacoronaviruses. Nature microbiology, v. 5, n. 4, p. 562-569, 2020.

Lorenzetti, E., de Arruda Leme, R., Ribeiro, J., De Souza, V. R. A., Alfieri, A. F., \& Alfieri, A. A. (2013). Neonatal diarrhea by bovine coronavirus (BCoV) in beef cattle herds. Semina: Ciências Agrárias, 34(2), 3795-3800.

Manzanares-Meza, L. D., \& Medina-Contreras, O. (2020). SARS-CoV-2 and influenza: a comparative overview and treatment implications. Boletín médico del Hospital Infantil de México, 77(5), 262-273.

Nascimento, U. F. S., Melo, E. D. O. L., de Matos Santana, V. L., Melo, A. P. A., de Souza Correia, Y. R. T., Bomfim, J. V. O., ... \& Rizzo, H. (2020). Coronavírus bovino: Revisão. PUBVET, 15, 181.

Pavarini, S. P. (2009). Achados clínicos e patológicos em casos naturais e experimentais de disenteria de inverno em bovinos adultos.

RECK, M. (2009). Diarreia neonatal bovina. 2009. 21f. Monografia (Graduação em Medicina Veterinária)-Universidade Federal do Rio Grande do Sul. Rio Grande do Sul.

Suphoronski, S. A., Lorenzetti, E., Ribeiro, J., Medeiros, T., Pannunzio, C., Possati, F., ... \& Alfieri, A. A. (2016). Perfil da infecção entérica por rotavirus e coronavírus em bezerros de corte lactentes criados em sistema extensivo na região centro-oeste, Brasil. Revista de Ciência Veterinária e Saúde Pública, 3, 124-126.

Uzunian, A. (2020). Coronavírus SARS-CoV-2 e Covid-19.

Van Doremalen, N., Bushmaker, T., Morris, D. H., Holbrook, M. G., Gamble, A., Williamson, B. N., ... \& Munster, V. J. (2020). Aerosol and surface stability of SARS-CoV-2 as compared with SARS-CoV-1. New England journal of medicine, 382(16), 1564-1567.

Vargas Júnior, S. F. (2015). Diarreia em bezerros na região sul do Rio Grande do Sul (Master's thesis, Universidade Federal de Pelotas).

Vieira, L. M. F., Emery, E., \& Andriolo, A. (2020). COVID-19: laboratory diagnosis for clinicians. An updating article. Sao Paulo Medical Journal, 138, 259266. 